\title{
Ethyl pyruvate suppresses the growth, invasion and migration and induces the apoptosis of non-small cell lung cancer cells via the HMGB1/RAGE axis and the NF-кB/STAT3 pathway
}

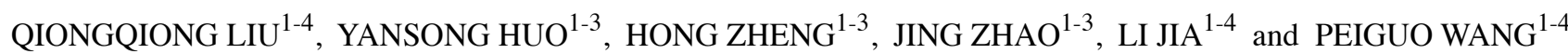 \\ ${ }^{1}$ Tianjin Medical University Cancer Institute and Hospital, National Clinical Research Center for Cancer; \\ ${ }^{2}$ Key Laboratory of Cancer Prevention and Therapy; ${ }^{3}$ Tianjin Clinical Research Center for Cancer; \\ ${ }^{4}$ Department of Radiotherapy, Tianjin Medical University Cancer Institute and Hospital, Tianjin 300060, P.R. China
}

Received January 6, 2019; Accepted May 28, 2019

DOI: $10.3892 / o r .2019 .7176$

\begin{abstract}
As an inhibitor of high mobility group protein B1 (HMGB1), ethyl pyruvate (EP) has been associated with various inflammatory diseases. Recent studies have investigated the relationship between EP and cancer. The present study aimed to determine the antitumor efficacy of EP in non-small cell lung cancer (NSCLC) cells and elucidate the underlying mechanism. A549, H520 and PC-9 cells were treated with EP in suitable concentrations. RT-qPCR and western blot analysis were performed to evaluate HMGB1 and RAGE expression levels. MTT and colony formation assays assessed the effect of EP on cell growth. A Transwell assay was used to evaluate invasion and migration potential and flow cytometry was performed to analyze cell apoptosis. Bcl-2 family proteins were identified by western blot analysis. The results demonstrated that an increased EP concentration effectively reduced HMGB1 and RAGE expression, thus inhibiting the HMGB1/RAGE axis. EP decreased level of PCNA and MMP-9 and increased P53 levels. Bcl-2 and Mcl-1 were also decreased, whereas Bax expression was increased. Furthermore, a high concentration of EP (30 mmol/l) signifi-

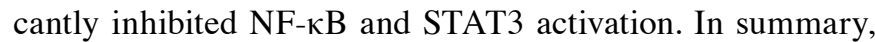
EP inhibited NSCLC cell growth, invasion and migration and induced apoptosis by suppressing the HMGB1/RAGE axis and the NF- $\kappa$ B/STAT3 pathway, thus suggesting that EP may be a valuable therapeutic agent for NSCLC.
\end{abstract}

\section{Introduction}

Lung cancer is a leading cause of cancer-related mortality, with non-small cell lung cancer (NSCLC) accounting for $\sim 80 \%$ of

Correspondence to: Dr Peiguo Wang, Department of Radiotherapy, Tianjin Medical University Cancer Institute and Hospital, Huanhu West Road, Tianjin 300060, P.R. China

E-mail:wpg2017@163.com

Key words: non-small cell lung cancer cells, ethyl pyruvate, high mobility group protein B1, growth, apoptosis, migration, invasion all lung cancer cases. Lung cancer incidence and mortality have significantly increased worldwide (1). The 5-year overall survival (OS) rate is only $15 \%$ among patients treated with traditional chemotherapeutic drugs due to the development of side effects and drug resistance. Approximately 1.7 million patients worldwide succumb to lung cancer yearly (2). It is therefore important to identify new therapies that may prolong the survival of lung cancer patients.

Cytokines, including inflammatory factors in the microenvironment, affect tumor cell proliferation and survival $(3,4)$. Various inflammatory factors, including TNF- $\alpha$, IL-6 and IL-8, promote tumor growth through Toll-like receptor (TLR)-mediated signaling pathways, thus promoting ERK, $\mathrm{NF}-\kappa \mathrm{B}$ and STAT3 activation (5-7). Damage-associated molecular patterns (DAMPs) are released by stressed, injured or dying cells, and initiate non-infectious inflammatory responses $(8,9)$. High mobility group protein B1 (HMGB1), one of the DAMPs, is released from damaged, inflamed, and cancerous cells, in turn promoting tumor cell survival through its receptor RAGE. HMGB1, which organizes DNA and regulates transcription, has various biological functions in and outside the cell, and promotes inflammation and tumorigenesis. The HMGB1/RAGE axis may cause pro-inflammatory gene activation (10). Due to enhanced levels of HMGB1 in certain chronic diseases, the RAGE receptor is believed to exert a promoting effect in inflammatory diseases and various tumors. NF- $\kappa \mathrm{B}$ is a heterodimeric protein belonging to the Rel family, and plays a major role in stress-induced immune and inflammatory responses (11). It was previously demonstrated that the NF- $\mathrm{NB}$ transcription factor group has an important association with tumor progression by affecting programmed cell death, proliferation control and tumorigenesis (12). Recent studies suggest that STAT proteins (particularly STAT3) play a crucial role in the carcinogenic inflammatory microenvironment at the early stages of malignant transformation, as well as during cancer progression $(13,14)$. Several human malignancies, including lymphoma, leukemia and multiple myeloma, are associated with STAT3 (15). Therefore, inhibiton of STAT3 signaling may be a promising approach to cancer treatment.

Ethyl pyruvate (EP), a lipophilic ester, is derived from pyruvic acid and is a non-toxic food additive $(16,17)$. EP has 
pharmacological benefits, namely alleviation of redox-caused cellular and tissue damage (18), anti-inflammatory properties $(19,20)$ and promotion of apoptosis (21). EP inhibits HMGB1 release (22). Although EP may suppress various tumors to different degrees, its effect on lung cancer remains unclear. The aim of the present study was to investigate whether EP exerts antitumor effects on lung cancer cells and elucidate the underlying mechanism.

\section{Materials and methods}

Materials. The NSCLC cell lines A549, H520 and PC-9 were obtained from Tianjin Medical University Cancer Institute. The primers for HMGB1, RAGE, MMP-9, PCNA, P53 and ACTIN were all obtained from Invitrogen; Thermo Fisher Scientific, Inc. HMGB1 (cat. no. ab227168), RAGE (cat. no. ab3611), MMP-9 (cat. no. ab38898) antibodies were all purchased from Abcam. ACTIN (cat. no. sc-58673), GAPDH (cat. no. sc-365062), P53 (cat. no. sc-126), pCNA (cat. no. sc-9857), Bax (cat. no. sc-4239), Bcl-2 (cat. no. sc-7382), Mcl-1 (cat. no. sc-12756) and STAT3 (cat. no. sc-8019) antibodies were purchased from Santa Cruz Biotechnology, Inc. The antibodies against NF-кB (cat. no. 8242), p-NF- $\kappa$ B (cat. no. 3033 and p-STAT3 (cat. no. 9131) were all purchased from Cell Signaling Technology, Inc.

Drugs and reagents. MTT was purchased from Roche Molecular Biochemicals. EP was purchased from Sigma-Aldrich; Merck KGaA and RPMI-1640 from Thermo Fisher Scientific, Inc. Fetal bovine serum (FBS) was obtained from Gibco; Thermo Fisher Scientific, Inc. and TRIzol reagent was purchased from Invitrogen; Thermo Fisher Scientific, Inc. The PrimeScript RT Reagent kit (Perfect Real-Time) and SYBR Premix Ex Taq (Tli RNaseH Plus) were obtained from Takara Biotechnology Co., Ltd. The cell apoptosis kit with propidium iodide and Annexin V-FITC was from BD Pharmingen.

Cell culture. The cell lines A549, H520 and PC-9 were all cultured in RPMI-1640 medium. All three cultures were supplemented with $10 \%$ FBS, penicillin (100 U/ml) and streptomycin $(100 \mathrm{mg} / \mathrm{ml})$. The cell lines were all maintained at $37^{\circ} \mathrm{C}$ in a humidified atmosphere containing $5 \% \mathrm{CO}_{2}$.

MTT assay. The MTT assay was used to analyze cell growth. Following treatment with EP, the cells were incubated in a 96-well-plate at a density of $3 \times 10^{4}$ cells/well. MTT $(10 \mu 1$, $5 \mathrm{mg} / \mathrm{ml}$ ) was added to the wells at $0,1,2,3$ and 4 days of culture. After incubation for $2 \mathrm{~h}$, the crystals were dissolved by adding DMSO (150 $\mu \mathrm{l} /$ well $)$ and mixed well with a multichannel pipette. The optical density (OD) of the soluble formazan in each well was measured at $490 \mathrm{~nm}$ with a microplate reader (Thermo Fisher Scientific, Inc.). All experiments were performed in triplicate.

$R T$ - $q P C R$. mRNA expression levels were determined by RT-qPCR. Total RNA was extracted with TRIzol according to the manufacturer's specifications. Reverse transcription was carried out using a Prime Script RT Reagent kit (Perfect Real-Time) and cDNA amplification was conducted using SYBR Premix Ex Taq (Tli RNaseH Plus) according to the manufacturer's instructions. Target genes were amplified using oligonucleotide primers. The ACTIN gene was used as
Table I. Primer sequences for PCR.

\begin{tabular}{|c|c|}
\hline Genes & Primer sequences $\left(5^{\prime} \rightarrow 3^{\prime}\right)$ \\
\hline \multirow[t]{2}{*}{$H M G B 1$} & Forward ATATGGCAAAAGCGGACAAG \\
\hline & Reverse AGGCCAGGATGTTCTCCTTT \\
\hline \multirow[t]{2}{*}{$R A G E$} & Forward GTCATGGAACTGCCCAAACT \\
\hline & Reverse TCCTTCTGCGGATCTGTCTT \\
\hline \multirow[t]{2}{*}{ PCNA } & Forward GCCGAGATCTCAGCCATATT \\
\hline & Reverse ATGTACTTAGAGGTACAAAT \\
\hline \multirow[t]{2}{*}{$M M P-9$} & Forward CGCAGACATCGTCATCCAGT \\
\hline & Reverse GGATTGGCCTTGGAAGATG \\
\hline \multirow[t]{2}{*}{ P53 } & Forward AACGGTACTCCGCCACC \\
\hline & Reverse CGTGTCACCGTCGTGGA \\
\hline \multirow[t]{2}{*}{ ACTIN } & Forward CTGGAACGGTGAAGGTGACA \\
\hline & Reverse AAGGGACTTCCTGTAACAATGC \\
\hline
\end{tabular}

endogenous control. The PCR primer sequences are listed in Table I. Data were analyzed using the comparative Cq method $\left(2^{-\Delta \Delta \mathrm{Cq})}\right.$ (23). Each experiment was conducted in triplicate.

Western blot analysis. The cells of each group were collected and treated with $\operatorname{EP}(0,5,10,20$ and $30 \mathrm{mmol} / \mathrm{l})$. Subsequently, proteins were extracted with CellLytic M cell Lysis Reagent with protease inhibitor and phosphatase inhibitor cocktails (all from Sigma-Aldrich; Merck KGaA). The proteins were quantified using a BCA protein assay kit. Proteins $(30 \mu \mathrm{g})$ were separated by $10 \%$ SDS-PAGE. Polyvinylidene difluoride (PVDF) membrane were blocked with a blocking reagent [Tris-buffered saline-0.1\% Tween-20 (TBST) containing 5\% polyvinyl pyrrolidone (PVP), 5\% FBS] at room temperature for $1 \mathrm{~h}$ and then incubated with primary antibody (dilution 1:1,000) overnight at $4^{\circ} \mathrm{C}$. After washing the membranes three times, PVDF membranes were incubated with HRP-conjugated secondary antibodies (Cell Signaling Technology; dilution 1:2,000) for $1 \mathrm{~h}$ at normal temperature. Immunoreactive bands were visualized by an Imaging System (Tanon Science and Technology) after adding chemiluminescent HRP substrate (Millipore Corp.). Each experiment was conducted in triplicate.

Colony formation assay. The A549, H520 and PC-9 cells were treated with EP and seeded in 6-well plates with 800 cells/clone. The culture medium was replaced every 3 days. Colonies were counted when visible with the naked eye. The cells were then fixed with methanol and stained with 5\% crystal violet solution. Each experiment was conducted in triplicate.

Cell apoptosis analysis. The percentage of apoptotic cells was calculated by means of an Annexin-V fluorescein isothiocyanate (FITC) and propidium iodide (PI) apoptosis detection kit (BD Biosciences) according to the manufacturer's instructions. The percentage of apoptotic cells $\left(\right.$ Annexin $\left.{ }^{+} / \mathrm{PI}^{+}\right)$was analyzed via flow cytometry (BD Biosciences). Each experiment was conducted in triplicate.

Transwell assay. Transwell chambers $(8 \mu \mathrm{m})$ were used for cell migration and invasion assays (Corning, Inc.). For the migration 

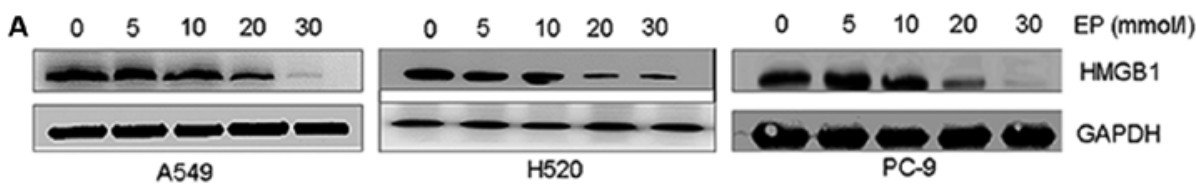

$29 \mathrm{kDa}$

$37 \mathrm{kDa}$
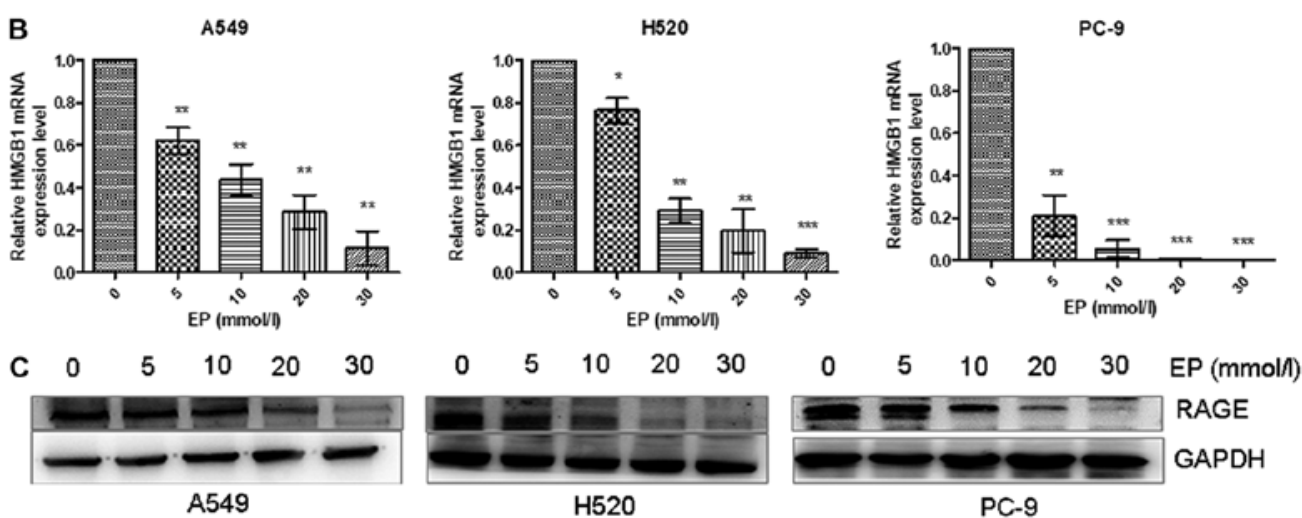

$45 \mathrm{kDa}$

$37 \mathrm{kDa}$
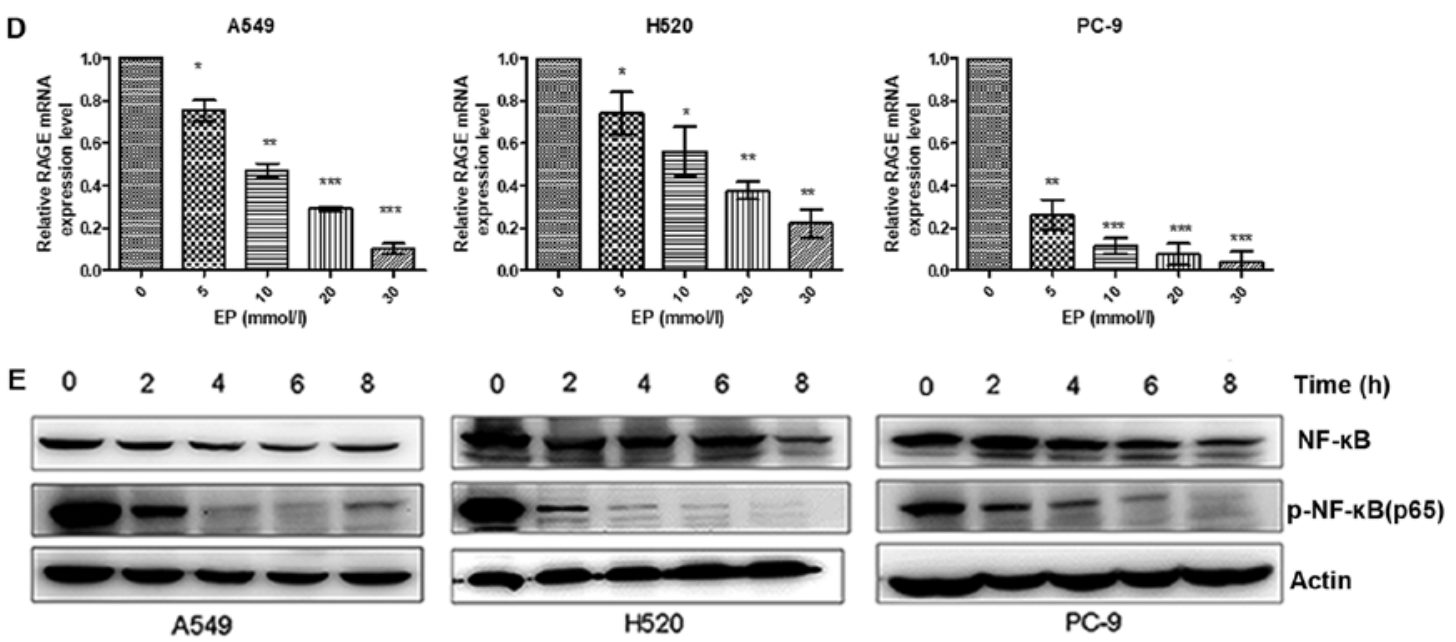

$65 \mathrm{kDa}$

$65 \mathrm{kDa}$

$43 \mathrm{kDa}$
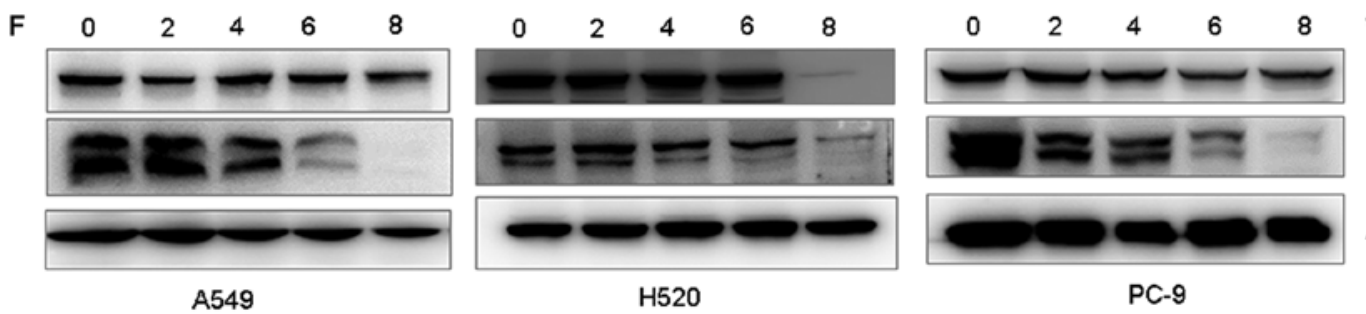

Time (h)

STAT3 86 kDa

p-STAT3 $86 \mathrm{kDa}$

Actin

$43 \mathrm{kDa}$

Figure 1. Effects of EP administration on the expression of the HMGBI/RAGE axis and the NF-кB/STAT3 pathway in lung cancer cell lines. (A and B) The protein and mRNA expression levels of HMGB1 as determined by western blot analysis and qPCR were decreased in EP-treated groups in a dose-dependent manner compared with the control group. (C and D) qPCR and western blot analysis were used to measure the RAGE mRNA and protein levels, respectively, in A549, H520 and PC-9 cells. The RAGE levels were significantly reduced in EP-treated groups in a dose-dependent manner compared with the control group. (E) Western blot analysis revealed that the expression level of p-NF- $\mathrm{kB}$ was decreased in the EP-treated groups in a time-dependent manner (at 2, 4, 6 and $8 \mathrm{~h}$ ) compared with the control group $(0 \mathrm{~h})$. (F) The protein levels of p-STAT3 were determined by western blot analysis in A549, H520 and PC-9 cells, and were found to be significantly reduced by treatment with $30 \mathrm{mmol} / 1 \mathrm{EP}$ in a time-dependent manner compared with the control group. ${ }^{*} \mathrm{P}<0.05,{ }^{* * *} \mathrm{P}<0.01$ and ${ }^{* * * * *} \mathrm{P}<0.001$ as compared to the $0 \mathrm{mmol} / \mathrm{l}$ EP group. EP, ethyl pyruvate; HMGB1, high mobility group protein $\mathrm{B} 1$.

assay, $1 \times 10^{5}$ cells were harvested and seeded on the upper chamber. For the invasion assay, $3 \times 10^{5}$ cells were harvested and placed in the upper chamber coated with Matrigel $(300 \mu \mathrm{g} / \mathrm{ml}, 100 \mu \mathrm{l})$. RPMI-1640 (600 $\mu \mathrm{l})$ supplemented with 20\% FBS was added to the lower chamber. The migrating or invading cells were fixed with $100 \%$ methanol for 30 min and stained with 5\% crystal violet solution for 8 min post $24 \mathrm{~h}$. Cells in 5 random fields ( $\mathrm{x} 4$ ) were calculated using Nikon MA100 optical microscope (Nikon Corp., Tokyo. Japan). Each assay was performed in triplicate.
Statistical analysis. All statistical analyses were carried out using SPSS 17.0 software (SPSS, Inc., Chicago, IL, USA). Results are presented as mean \pm standard deviation. The capability of cell migration and invasion between $20 \mathrm{mmol} / 1 \mathrm{EP}$ and $0 \mathrm{mmol} / \mathrm{LP}$ in Fig. 3 (bar graph) were calculated using independent sample t-tests. Furthermore, the statistical analysis method used for the data of mRNA expression level and cell apoptosis index in Figs. 1, 2 and 4 (bar graphs) was the Kruskal-Wallis followed by Dunnett's post hoc test when the $0 \mathrm{mmol} / \mathrm{l} \mathrm{EP}$ group was 

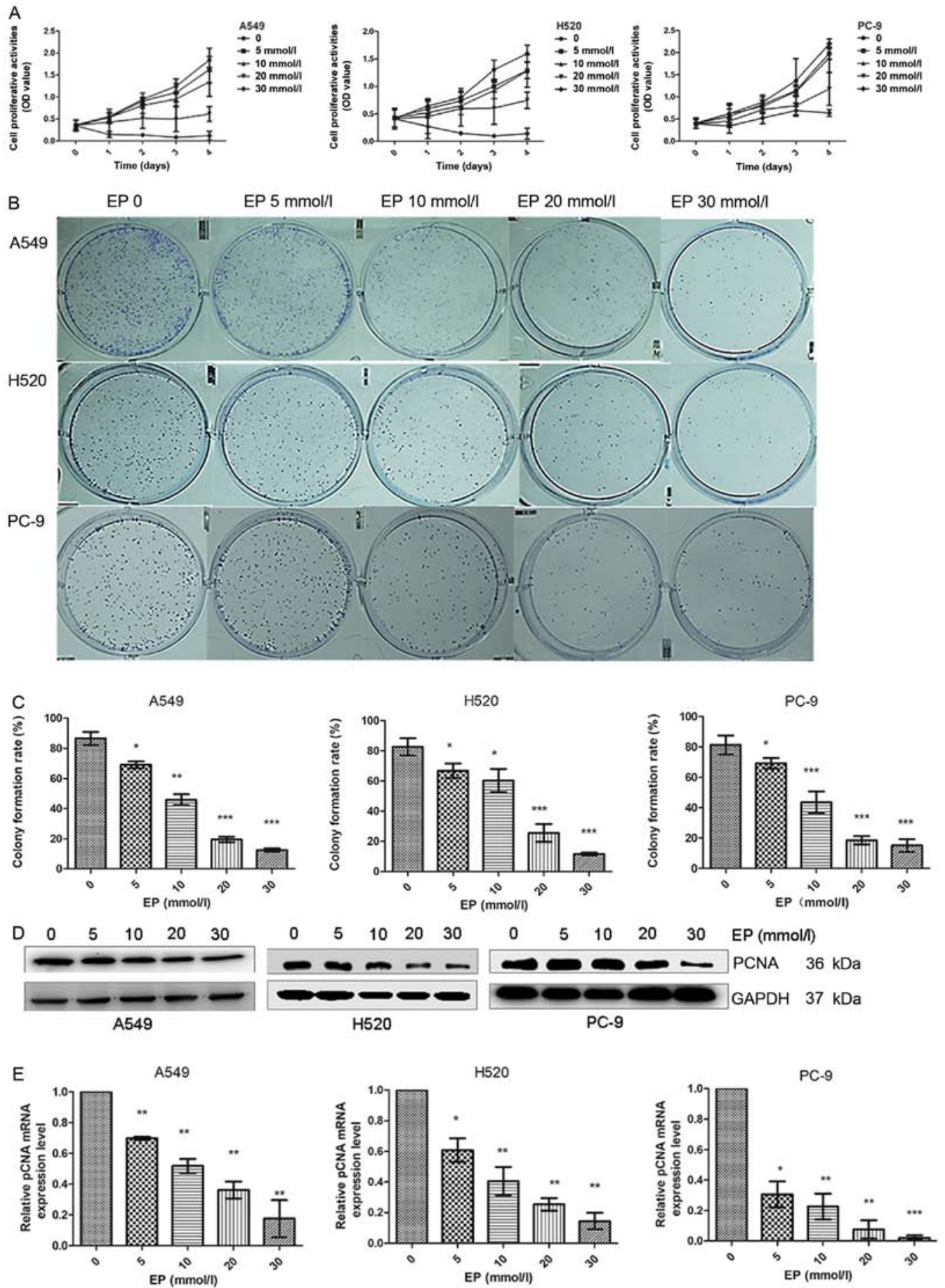

Figure 2. EP administration suppresses lung cancer cell proliferation and independent growth. (A) A549, H520 and PC-9 cells were treated with gradually increasing concentrations of EP (0-30 mmol/l) and the dose-dependent anti-growth effect was detected by MTT assay. (B and C) Independent cell growth activity was evaluated by colony formation assay. A549, H520 and PC-9 cells were treated with gradually increasing concentrations of EP prior to seeding in 6-well plates. The number of colonies were counted from day 10 onwards and the colony formation rate was calculated and presented as a histogram. (D) The PCNA protein level was detected by western blot analysis. GAPDH protein was used as an endogenous control. (E) The PCNA expression level was measured in A549, H520 and PC-9 cells treated with different concentrations of EP by qPCR and was found to be decreased by EP in a dose-dependent manner. ${ }^{*} \mathrm{P}<0.05,{ }^{* * *} \mathrm{P}<0.01$ and ${ }^{* * * *} \mathrm{P}<0.001$ as compared to the $0 \mathrm{mmol} / 1 \mathrm{EP}$ group. EP, ethyl pyruvate; HMGB1, high mobility group protein B1; PCNA, proliferating cell nuclear antigen.

compared with the 5, 10, 20 and $30 \mathrm{mmol} / \mathrm{l}$ EP groups. $\mathrm{P}<0.05$ was considered to indicate a statistically significant difference.

\section{Results}

Administration of EP suppresses the expression of the $H M G B 1 / R A G E$ axis and the NF- $\kappa B / S T A T 3$ pathway in lung cancer cells. RAGE, also known as AGER, is a transmembrane receptor that binds to a variety of ligands, including HMGB1 $(24,25)$. A549, H520 and PC-9 cells were treated with $\mathrm{EP}(0,5,10,20$ and $30 \mathrm{mmol} / \mathrm{l})$ in order to investigate its effects on HMGB1 and RAGE protein as well as mRNA expression. The protein and mRNA expression levels of HMGB1 were significantly decreased with increasing EP dose 

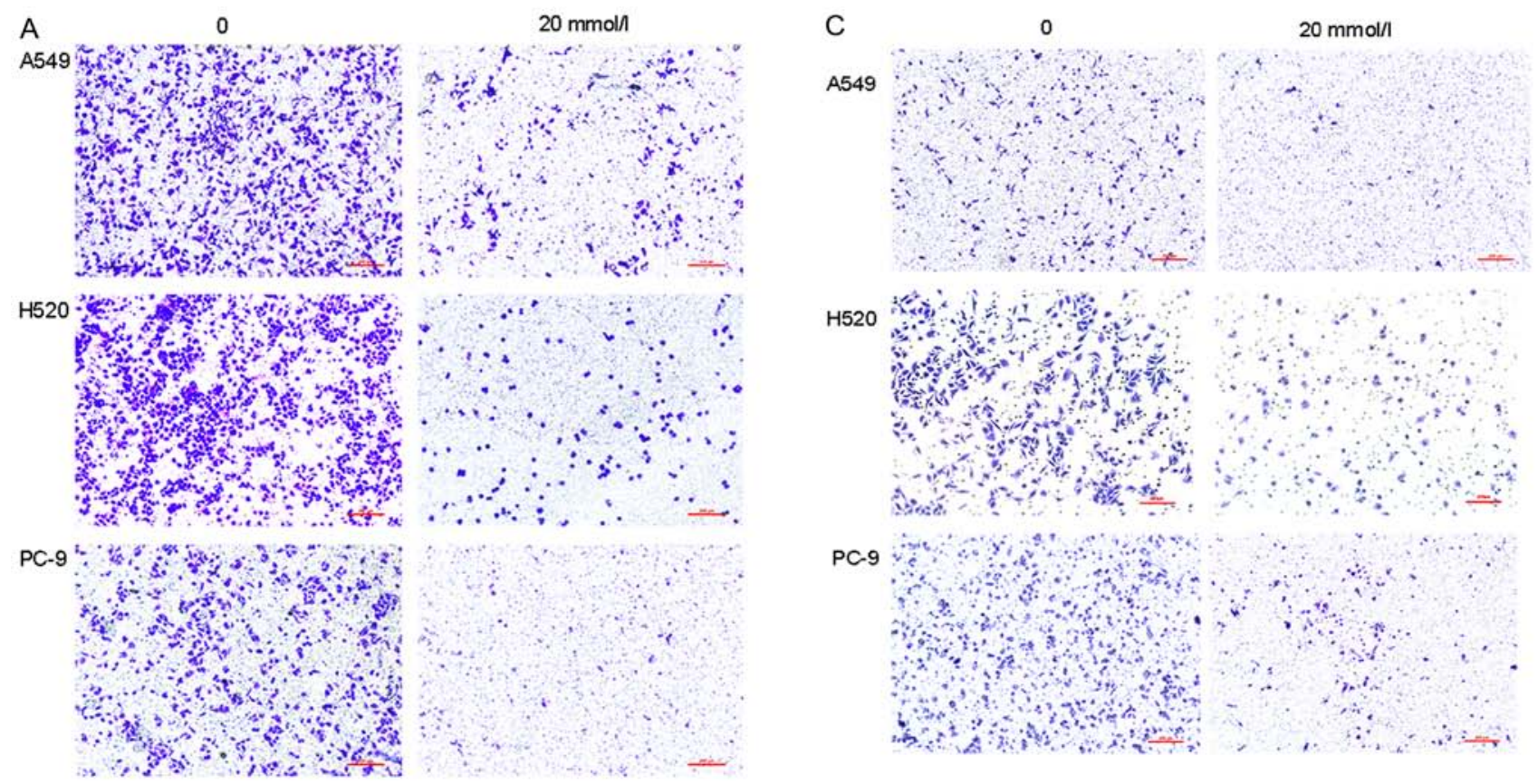

B

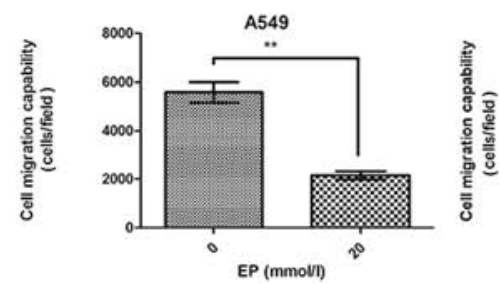

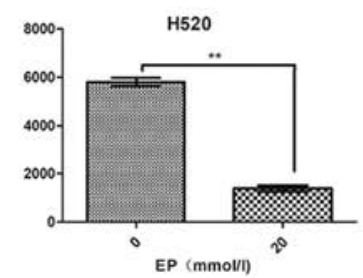

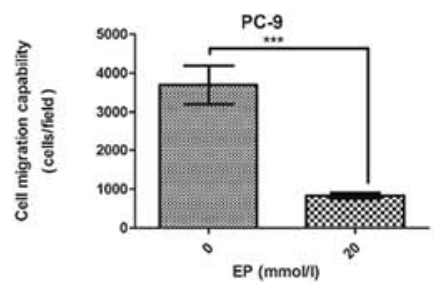

D
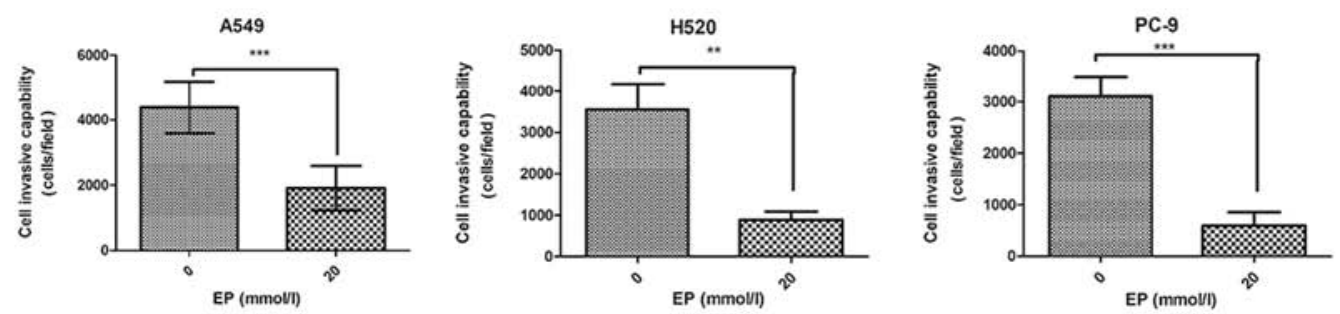

E
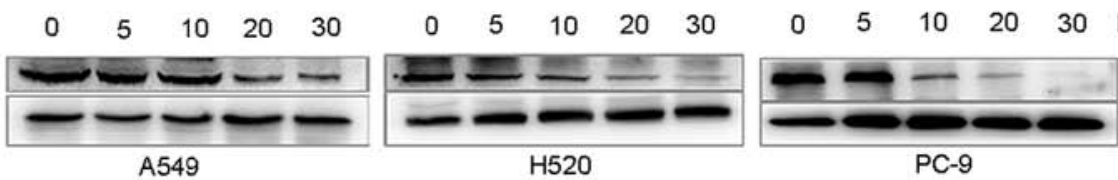

F

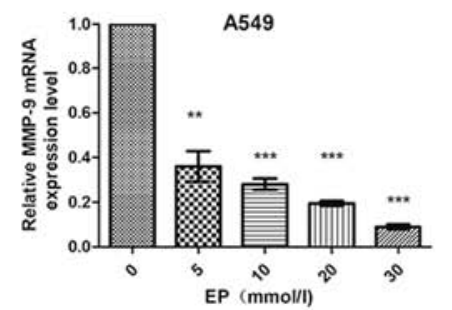

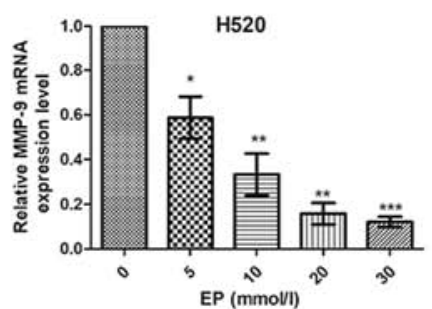

PC-9

MMP-9 $92 \mathrm{kDa}$

GAPDH $\quad 37 \mathrm{kDa}$

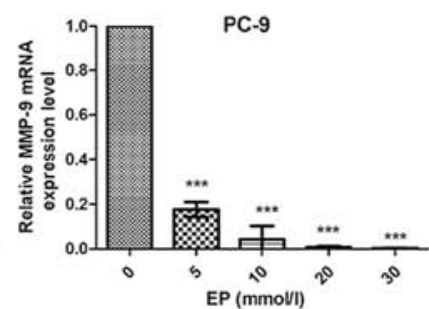

Figure 3. EP administration suppresses lung cancer cell migration and invasion. (A-D) Transwell assay was performed to determine cell invasion and migration ability. EP treatment significantly reduced the invasive activity of A549, H520 and PC-9 cells in the presence or absence of Matrigel compared with control (untreated) cells. (E) The expression level of MMP-9 was detected by western blot analysis. GAPDH was used as an endogenous control. (F) The expression levels of MMP-9 measured in A549, H520 and PC-9 cells treated with different concentrations of EP by qPCR were decreased in a dose-dependent manner. ${ }^{*} \mathrm{P}<0.05,{ }^{* *} \mathrm{P}<0.01$ and ${ }^{* * *} \mathrm{P}<0.001$ as compared to the $0 \mathrm{mmol} / 1 \mathrm{EP}$ group. EP, ethyl pyruvate; MMP-9, matrix metallopeptidase 9.

(Fig. 1A and B). Similarly, the mRNA and protein expression levels of RAGE were also decreased with increasing EP dose (Fig. 1C and D).
$\mathrm{NF}-\kappa \mathrm{B}$ regulates DNA transcription, cytokine production and cell survival (26). In the present study, A549, H520 and PC-9 cells were treated with $30 \mathrm{mmol} / \mathrm{l} \mathrm{EP}$ for 2, 4, 6 and $8 \mathrm{~h}$ 

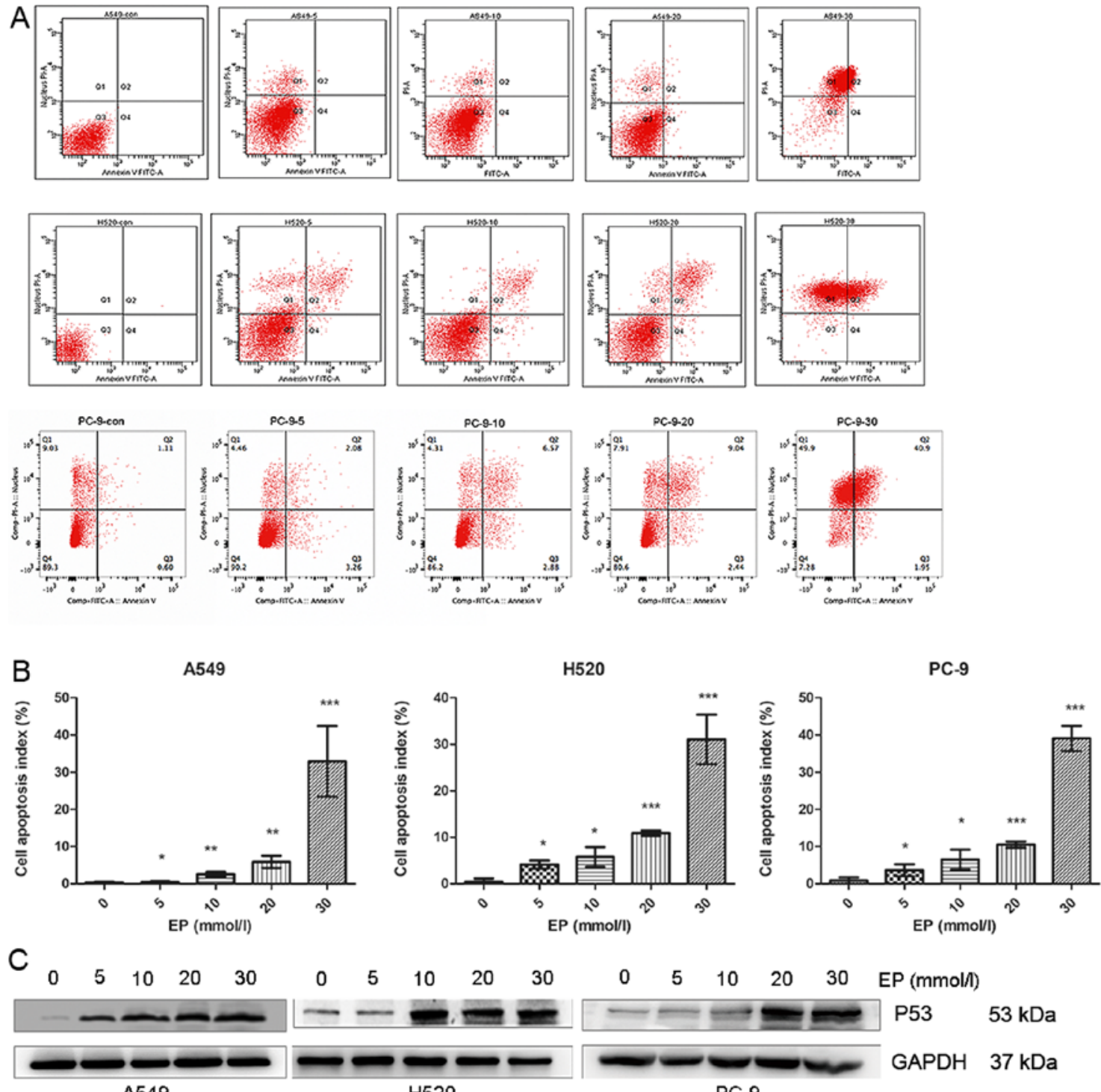

A549

$\mathrm{H} 520$
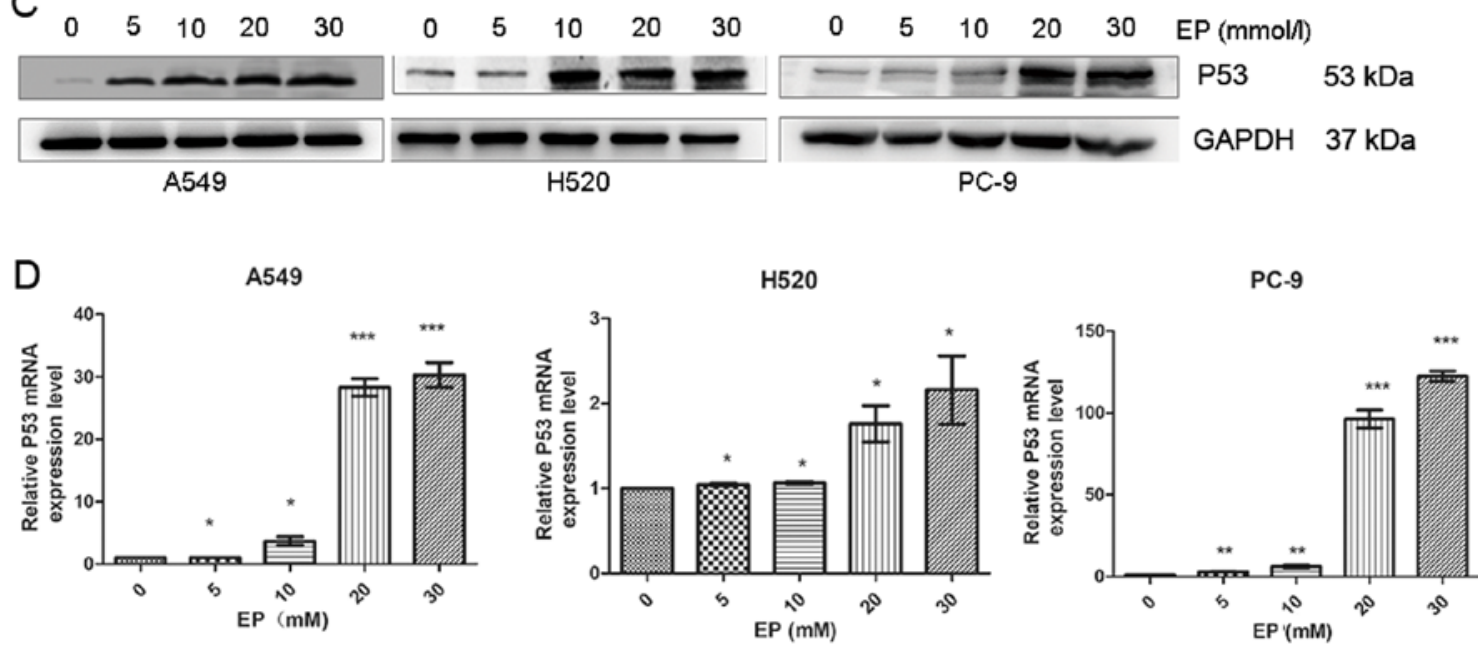

E

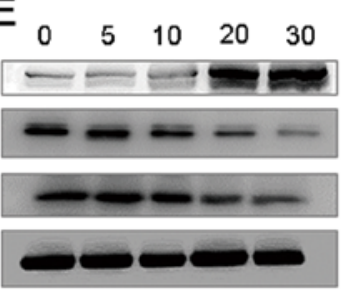

A549

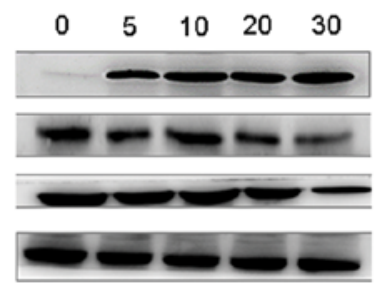

$\mathrm{H} 520$

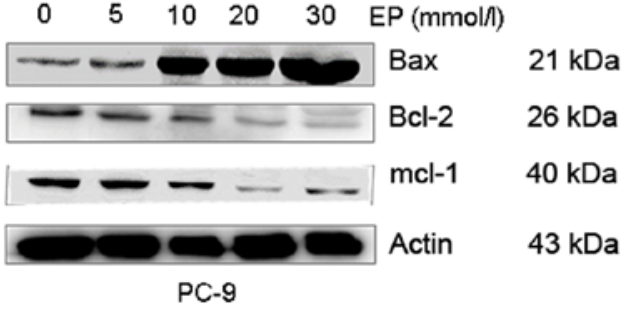

Figure 4. EP administration induces the apoptosis of lung cancer cells. (A and B) Flow cytometry with PI/FITC-Annexin V staining was performed to determine cell apoptosis. The apoptotic index of A549, H520 and PC-9 cells treated with gradually increasing concentrations of EP was markedly higher compared with that of the untreated cells. (C) The expression level of p53 was detected by western blot analysis and GAPDH was used as an endogenous control. (D) qPCR was used to investigate the effect of EP on p53 mRNA level. The mRNA level of p53 was increased in EP-treated groups compared with the control group. GAPDH was used as an endogenous control. (E) The expression of Bcl-2, Mcl-1 and Bax at the protein level was evaluated by western blot analysis. ACTIN was used as an endogenous control. ${ }^{*} \mathrm{P}<0.05,{ }^{* *} \mathrm{P}<0.01$ and ${ }^{* * *} \mathrm{P}<0.001$ as compared to the 0 mmol/1 EP group. EP, ethyl pyruvate. 
in order to examine NF- $\kappa \mathrm{B}$ and $\mathrm{p}-\mathrm{NF}-\kappa \mathrm{B}$ levels. The protein expression of $\mathrm{p}-\mathrm{NF}-\kappa \mathrm{B}$ was gradually decreased over time (Fig. 1E). STAT3 is a member of the STAT protein family (27). A549, H520, PC-9 cells were treated with $30 \mathrm{mmol} / 1 \mathrm{EP}$ for 2, 4, 6 and $8 \mathrm{~h}$ in order to examine STAT3 and p-STAT3 levels. The protein expression level of p-STAT3 was also decreased over the specified time period (Fig. 1F).

Administration of EP suppresses the growth of lung cancer cells. A hallmark of cancer is enhanced cell proliferation (28). A549 H520 and PC-9 cell growth was assessed via MTT and colony formation assays. It was observed that A549, H520 and PC-9 cell growth was markedly suppressed by EP in a dose/time-dependent manner (Fig. 2A). The colony formation rate of A549, H520 and PC-9 cells was significantly decreased in the EP-treated groups (Fig. 2B and C).

Proliferating cell nuclear antigen (PCNA) is a DNA clamp that is essential for replication (29) and tumor progression. Therefore, anticancer treatment effectiveness may be determined by PCNA (30). PCNA was investigated by western blot analysis and RT-qPCR. The data demonstrated that the expression of PCNA was decreased in the EP-treated groups (Fig. 2D and E).

Administration of EP inhibits the migration and invasion of lung cancer cells. A Transwell assay demonstrated that the migration and invasion potential of A549, H520 and PC-9 cells in the EP-treated groups was reduced compared with that of the control group (Fig. 3A-D).

Matrix metallopeptidase 9 (MMP-9) participates in the degradation of the extracellular matrix (31). MMP-9 may be associated with the development of various human malignancies by affecting invasion, metastasis, growth and angiogenesis $(32,33)$. Western blot analysis revealed downregulation of MMP-9 (Fig. 3E). The results were consistent with those of RT-qPCR (Fig. 3F).

Administration of EP promotes apoptosis of lung cancer cells. Flow cytometry was used to determine whether EP affects the apoptotic process of lung cancer cells. The results demonstrated that the apoptotic index of A549, H520 and PC-9 cells in the EP-treated groups was significantly higher compared with that of the control group (Fig. 4A and B).

P53, a tumor suppressor, directly participates in the endogenous apoptotic pathway by interacting with members of the Bcl-2 family $(34,35)$. Western blot analysis and qPCR were used to determine P53 changes. The data demonstrated that the protein and mRNA levels of P53 increased with increasing EP concentration (Fig. 4C and D).

The Bcl-2 family plays an important role in the regulation of apoptosis, a type of programmed cell death. Bcl-2 family members may promote or inhibit apoptosis (36). Western blot analysis revealed that EP treatment increased the pro-apoptotic protein Bax and decreased the anti-apoptotic proteins $\mathrm{Bcl}-2$ and Mcl-1 (Fig. 4E).

\section{Discussion}

In the present study, it was established that ethyl pyruvate (EP), a lipophilic ester, suppressed lung cancer cell growth, invasion and migration in vitro, and promoted apoptosis. Our results showed that the EP-mediated suppression of lung cancer cell growth was mediated via inhibition of the HMGB1/RAGE axis and the NF- $\kappa \mathrm{B} / \mathrm{STAT} 3$ pathway.

The results revealed that inflammatory factors play an important role in tumor initiation and progression. As an anti-inflammatory drug, EP has been shown to decrease organ dysfunction in several inflammation-induced disease models $(19,20)$. Several trials have attempted to improve the overall surivial (OS) rate of cancer patients via EP administration. It was previously demonstrated that tumor progression may be suppressed by EP. The OS of animals in several tumor models, including hepatic, gastric, gallbladder cancer and mesothelioma, may be increased via EP (37-42). As an HMGB1 inhibitor, the antitumor effect of EP is mediated by inhibiting the HMGB1/RAGE axis $(37,40,42)$. Previous studies have investigated the expression levels of HMGB1 and its receptor RAGE in lung cancer (43), and reported that growth, invasion and migration of lung cancer cells are dependent on these signaling molecules (44). In the present study, a significant reduction in HMGB1 and RAGE protein levels was observed in EP-treated lung cancer cells. Furthermore, RT-qPCR demonstrated that HMGB1-induced RAGE mRNA expression was specifically suppressed by EP treatment. Therefore, the antitumor effects exerted by EP on lung cancer cell lines may be explained by disruption of the HMGB1/RAGE loop. Using varying concentrations of EP, decreased non-small cell lung cancer (NSCLC) cell growth, invasion and migration, as well as increased apoptosis, were observed. To the best of our knowledge, this is the first study to investigate EP as a potential therapeutic agent for NSCLC. NF- $\kappa \mathrm{B}$ has been found to be active in tumor cells; therefore, $\mathrm{NF}-\kappa \mathrm{B}$ suppression may prevent tumor cell proliferation, thus enhancing the effectiveness of antitumor agents $(45,46)$. STAT3 regulates gene expression and plays a critical role in a number of cellular processes, such as cell growth and apoptosis (47). In the present study, EP suppressed the RELA protein expression in a time-dependent manner in three lung cancer cell lines via phosphorylation of Ser536. In regards to the STAT3 pathway, EP suppressed STAT3 in a time-dependent manner via phosphorylation of its Tyr705 residue.

EP may be proven to be useful as an antitumor agent. Unlike other chemical compounds, EP is associated with no toxicity and has a good safety profile (16). EP is widely used as a food additive and is found in caramel, brandy, rum, chocolate and other food spices. Its lack of toxicity has been verified in several previous studies conducted on animal models. EP treatment in humans was also proven to be risk-free (48). Preclinical research has demonstrated that tumor cell sensitivity to other antitumor agents is significantly increased by inhibiting the release of HMGB1 via EP, and chemotherapy-related cytotoxicity is decreased by EP (49). This evidence strongly supports the use of EP as an adjuvant lung cancer therapy.

Moreover, human malignant mesothelioma (MM) arises from the malignant transformation of mesothelial cells in the pleura, peritoneum and pericardial cavity. In a recent study by Pellegrini et al, it was observed that HMGB1 targeting by EP inhibited the development of MM (39). EP was shown to suppress the viability, motility and migration of MM cell lines (REN, HP3 and PPM-MILL) by inhibiting the HMGB1/RAGE 
and NF- $\mathrm{KB}$ pathways. Furthermore, Pellegrini et al found that EP inhibited orthotopic tumor growth in MM xenografts. Similarly, in our present study, we found that EP suppressed the growth, invasion and migration and induced apoptosis of NSCLC cells via the HMGB1/RAGE axis and the NF- $\kappa$ B/STAT3 pathway. However, our findings were not tested in vivo. Taken together, the findings of Pellegrini et al (39) and those of the present study indicate that EP may be useful as an adjuvant treatment for thoracic malignancies.

\section{Acknowledgements}

Not applicable.

\section{Funding}

The present study was supported by the National Science Foundation (NNSF) of China (grant no. 81570194 to LJ).

\section{Availability of data and materials}

All the datasets generated and analyzed in the present study are included in this published manuscript.

\section{Authors' contributions}

QL, PW, LJ and YH conceived and designed the study. QL, $\mathrm{HZ}$ and $\mathrm{JZ}$ performed the experiments. QL, $\mathrm{PW}$ and $\mathrm{YH}$ wrote the manuscript. QL, YH, HZ, JZ and LJ reviewed and edited the manuscript. All authors read and approved the manuscript and agree to be accountable for all aspects of the research in ensuring that the accuracy or integrity of any part of the work are appropriately investigated and resolved.

\section{Ethics approval and consent to participate}

Not applicable.

\section{Patient consent for publication}

Not applicable.

\section{Competing interests}

The authors declare that they have no competing interests.

\section{References}

1. Zou S, Pan X, Hua C, Wu M, He B and Chen Z: Myeloperoxidase- $463 \mathrm{G} / \mathrm{A}$ polymorphism is associated with lung cancer risk: A meta-analysis with 7420 cases and 9132 controls. J Cancer Res Ther 14 (Suppl): S282-S287, 2018.

2. Ziebarth NR: Lung cancer risk perception biases. Prev Med 110: $16-23,2018$.

3. Liu FT, Jia L, Wang P, Farren T, Li H, Hao X and Agrawal SG: CD126 and targeted therapy with tocilizumab in chronic lymphocytic leukemia. Clin Cancer Res 22: 2462-2469, 2016

4. Park BS, Jo HW, Park C, Huh Y, Jung J and Jeong NY: A novel effect of ethyl pyruvate in Schwann cell de-differentiation and proliferation during Wallerian degeneration. Anim Cells Syst 19: 262-268, 2015

5. Li X, Jiang S and Tapping RI: Toll-like receptor signaling in cell proliferation and survival. Cytokine 49: 1-9, 2010.
6. Gruffaz M, Vasan K, Tan B, Ramos da Silva S and Gao SJ: TLR4-mediated inflammation promotes KSHV-induced cellular transformation and tumorigenesis by activating the STAT3 pathway. Cancer Res 77: 7094-7108, 2017.

7. Su X, Wang H, Zhao J, Pan H and Mao L: Beneficial effects of ethyl pyruvate through inhibiting high-mobility group box 1 expression and TLR4/NF- $\kappa \mathrm{B}$ pathway after traumatic brain injury in the rat. Mediators Inflamm 2011: 807142, 2012.

8. Shao Y, Nanayakkara G, Cheng J, Cueto R, Yang WY, Park JY, Wang $\mathrm{H}$ and Yang $\mathrm{X}$ : Lysophospholipids and their receptors serve as conditional DAMPs and DAMP receptors in tissue oxidative and inflammatory injury. Antioxid Redox Signal, Apr 26, 2017 (Epub ahead of print). doi: 10.1089/ars.2017.7069.

9. Lin TJ, Lin HT, Chang WT, Mitapalli SP, Hsiao PW, Yin SY and Yang NS: Shikonin-enhanced cell immunogenicity of tumor vaccine is mediated by the differential effects of DAMP components. Mol Cancer 14: 174, 2015.

10. Bierhaus A, Schiekofer S, Schwaninger M, Andrassy M, Humpert PM, Chen J, Hong M, Luther T, Henle T, Klöting I, et al: Diabetes-associated sustained activation of the transcription factor nuclear factor-kappaB. Diabetes 50: 2792-2808, 2001.

11. Baldwin AS Jr: The NF-kappa B and I kappa B proteins: New discoveries and insights. Annu Rev Immunol 14: 649-683, 1996.

12. Müller M, Morotti A and Ponzetto C: Activation of NF-kappaB is essential for hepatocyte growth factor-mediated proliferation and tubulogenesis. Mol Cell Biol 22: 1060-1072, 2002.

13. Mantovani A, Allavena P, Sica A and Balkwill F: Cancer-related inflammation. Nature 454: 436-444, 2008.

14. Grivennikov S, Karin E, Terzic J, Mucida D, Yu GY, Vallabhapurapu S, Scheller J, Rose-John S, Cheroutre H, Eckmann L and Karin M: IL-6 and Stat3 are required for survival of intestinal epithelial cells and development of colitis-associated cancer. Cancer Cell 15: 103-113, 2009.

15. Shen Y, Devgan G, Darnell JE Jr and Bromberg JF: Constitutively activated Stat 3 protects fibroblasts from serum withdrawal and UV-induced apoptosis and antagonizes the proapoptotic effects of activated Stat1. Proc Natl Acad Sci USA 98: 1543-1548, 2001.

16. Pathak M, Mishra R, Agarwala PK, Ojha H, Singh B, Singh A and Kukreti S: Binding of ethyl pyruvate to bovine serum albumin: Calorimetric, spectroscopic and molecular docking studies. Thermochim Acta 633: 140-148, 2016.

17. Cook VL, Holcombe SJ, Gandy JC, Corl CM and Sordillo LM: Ethyl pyruvate decreases proinflammatory gene expression in lipopolysaccharide-stimulated equine monocytes. Vet Immunol Immunopathol 141: 92-99, 2011.

18. Wagner N, Dieteren S, Franz N, Köhler K, Mörs K, Nicin L, Schmidt J, Perl M, Marzi I and Relja B: Ethyl pyruvate ameliorates hepatic injury following blunt chest trauma and hemorrhagic shock by reducing local inflammation, NF-kappaB activation and HMGB1 release. PLoS One 13: e0192171. doi: 10.1371/journal. pone.0192171. eCollection 2018.

19. Wang FC, Xie Y and Zhou NJ: Ethyl pyruvate reduced h pyloriinduced inflammation through inhibition of HMGB1/TLR4 pathways. J Gastroenterol Hepatol 29: 27-27, 2014.

20. Shen HX, Hu XM, Liu C, Wang SP, Zhang WT, Gao H, Steder RA, Gao YQ and Chen J: Ethyl pyruvate protects against hypoxic-ischemic brain injury via anti-cell death and anti-inflammatory mechanisms. Neurobiol Dis 37: 711-722, 2010.

21. Shen M, Lu J, Dai W, Wang F, Xu L, Chen K, He L, Cheng P, Zhang Y, Wang C, et al: Ethyl pyruvate ameliorates hepatic ischemia-reperfusion injury by inhibiting intrinsic pathway of apoptosis and autophagy. Mediators Inflamm 2013: 461536, 2013.

22. Chakhtoura M, Chain R, Varghese L and Gallucci S: Ethyl pyruvate, an inhibitor of high-mobility group box 1 (HMGB1) release, modulates dendritic cell activation and survival (TRAN3P.897). J Immunol 192 (1 Suppl): S202-S236, 2014.

23. Livak KJ and Schmittgen TD: Analysis of relative gene expression data using real-time quantitative PCR and the 2(-Delta Delta C(T)) method. Methods 25: 402-408, 2011.

24. Ibrahim ZA, Armour CL, Phipps S and Sukkar MB: RAGE and TLRs: Relatives, friends or neighbours? Mol Immunol 56: 739-744, 2013.

25. Han SH, Kim YH and Mook-Jung I: RAGE: The beneficial and deleterious effects by diverse mechanisms of actions. Mol Cells 31: 91-97, 2011.

26. Perkins ND: Integrating cell-signalling pathways with NF-kappaB and IKK function. Nat Rev Mol Cell Biol 8: 49-62, 2007.

27. Yu H, Pardoll D and Jove R: STATs in cancer inflammation and immunity: A leading role for STAT3. Nat Rev Cancer 9: 798-809, 2009. 
28. Hanahan D and Weinberg RA: Hallmarks of cancer: The next generation. Cell 144: 646-674, 2011.

29. Actis M, Inoue A, Evison B, Perry S, Punchihewa C and Fujii N: Small molecule inhibitors of PCNA/PIP-box interaction suppress translesion DNA synthesis. Bioorg Med Chem 21: 1972-1977, 2013.

30. Abike F, Tapisiz OL, Zergeroglu S, Dunder I, Temizkan O and Payasli A: PCNA and Ki-67 in endometrial hyperplasias and evaluation of the potential of malignancy. Eur J Gynaecol Oncol 32: 77-80, 2011.

31. Himelstein BP, Canete-Soler R, Bernhard EJ, Dilks DW and Muschel RJ: Metalloproteinases in tumor progression: The contribution of MMP-9. Invasion Metastasis 14: 246-258, 1994.

32. Morini M, Mottolese M, Ferrari N, Ghiorzo F, Buglioni S, Mortarini R, Noonan DM, Natali PG and Albini A: The alpha 3 beta 1 integrin is associated with mammary carcinoma cell metastasis, invasion, and gelatinase B (MMP-9) activity. Int J Cancer 87: 336-342, 2000.

33. Farina AR and Mackay AR: Gelatinase B/MMP-9 in tumour pathogenesis and progression. Cancers (Basel) 6: 240-296, 2014

34. Zhang L, Ma L, Yan T, Han X, Xu J, Xu J and Xu X: Activated mitochondrial apoptosis in hESCs after dissociation involving the PKA/p-p53/Bax signaling pathway. Exp Cell Res 369: 226-233, 2018

35. Yao TH, Pataer P, Regmi KP, Gu XW, Li QY, Du JT, Ge SM and Tu JB: Propranolol induces hemangioma endothelial cell apoptosis via a p53-BAX mediated pathway. Mol Med Rep 18: 684-694, 2018

36. Youle RJ and Strasser A: The BCL-2 protein family: Opposing activities that mediate cell death. Nat Rev Mol Cell Biol 9: 47-59, 2008.

37. Zhang J, Zhu JS, Zhou Z, Chen WX and Chen NW: Inhibitory effects of ethyl pyruvate administration on human gastric cancer growth via regulation of the HMGB1-RAGE and Akt pathways in vitro and in vivo. Oncol Rep 27: 1511-1519, 2012.

38. Birkenmeier G, Hemdan NYA, Kurz S, Bigl M, Pieroh P, Debebe T, Buchold M, Thieme R, Wichmann G and Dehghani F: Ethyl pyruvate combats human leukemia cells but spares normal blood cells. PLoS One 11: e0161571, 2016.

39. Pellegrini L, Xue J, Larson D, Pastorino S, Jube S, Forest KH, Saad-Jube ZS, Napolitano A, Pagano I, Negi VS, et al: HMGB1 targeting by ethyl pyruvate suppresses malignant phenotype of human mesothelioma. Oncotarget 8: 22649-22661, 2017.
40. Cheng P, Dai W, Wang F, Lu J, Shen M, Chen K, Li JJ, Zhang Y, Wang C, Yang J, et al: Ethyl pyruvate inhibits proliferation and induces apoptosis of hepatocellular carcinoma via regulation of the HMGB1-RAGE and AKT pathways. Biochem Biophys Res Commun 443: 1162-1168, 2014.

41. Baunacke M, Horn LC, Trettner S, Engel KM, Hemdan NY, Wiechmann V, Stolzenburg JU, Bigl M and Birkenmeier G: Exploring glyoxalase 1 expression in prostate cancer tissues: Targeting the enzyme by ethyl pyruvate defangs some malignancy-associated properties. Prostate 74: 48-60, 2014.

42. Li ML, Wang XF, Tan ZJ, Dong P, Gu J, Lu JH, Wu XS, Zhang L, Ding QC, Wu WG, et al: Ethyl pyruvate administration suppresses growth and invasion of gallbladder cancer cells via downregulation of HMGB1-RAGE axis. Int J Immunopathol Pharmacol 25: 955-965, 2012.

43. Queisser MA, Kouri FM,Königshoff M, Wygrecka M, Schubert U, Eickelberg O and Preissner KT: Loss of RAGE in pulmonary fibrosis: Molecular relations to functional changes in pulmonary cell types. Am J Respir Cell Mol Biol 39: 337-345, 2008.

44. Xu X, Zhu H, Wang T, Sun Y, Ni P, Liu Y, Tian S, Amoah Barnie $\mathrm{P}$, Shen $\mathrm{H}, \mathrm{Xu} \mathrm{W}$, et al: Exogenous high-mobility group box 1 inhibits apoptosis and promotes the proliferation of lewis cells via RAGE/TLR4-dependent signal pathways. Scand J Immunol 79: 386-394, 2014.

45. Gilmore TD: Introduction to NF-kappaB: Players, pathways, perspectives. Oncogene 25: 6680-6684, 2006.

46. Escárcega RO,Fuentes-Alexandro S, Garcia-Carrasco M, Gatica A and Zamora A: The transcription factor nuclear factor-kappa B and cancer. Clin Oncol (R Coll Radiol) 19: 154-561, 2007.

47. Yuan ZL, Guan YJ, Wang L, Wei W, Kane AB and Chin YE: Central role of the threonine residue within the $p+1$ loop of receptor tyrosine kinase in STAT3 constitutive phosphorylation in metastatic cancer cells. Mol Cell Biol 24: 9390-9400, 2004.

48. Bennett-Guerrero E, Swaminathan M, Grigore AM, Roach GW, Aberle LG, Johnston JM and Fink MP: A phase II multicenter double-blind placebo-controlled study of ethyl pyruvate in high-risk patients undergoing cardiac surgery with cardiopulmonary bypass. J Cardiothorac Vasc Anesth 23: 324-329, 2009.

49. Tang D, Kang R, Cheh CW, Livesey KM, Liang X, Schapiro NE, Benschop R, Sparvero LJ, Amoscato AA, Tracey KJ, et al: HMGB1 release and redox regulates autophagy and apoptosis in cancer cells. Oncogene 29: 5299-5310, 2010. 